\title{
An Immunoinformatics Approach to Design Synthetic Peptide Vaccine from Dendroaspis polylepis polylepis Dendrotoxin-K(DTX-K)
}

\author{
Changbhale S.S ${ }^{1}$, Chitlange N.R ${ }^{2}$, Gomase V.S ${ }^{*}$ and Kale K.V ${ }^{3}$
}

${ }^{1}$ Department of Computer Science, Jagdishprasad Jhabarmal Tibrewala University, Jhunjhunu, Rajasthan, India

${ }^{2}$ Bioinformatics, Jagdishprasad Jhabarmal Tibrewala University, Jhunjhunu, Rajasthan, India

${ }^{3}$ Professor and Head, Department of Computer Science and Information Technology, Dr. Babasaheb Ambedkar Marathwada University, Aurangabad, India

\begin{abstract}
Dendroaspis polylepis polylepis is the most toxic snake commonly known as black mamba, the black mamba venom contains Dendrotoxin-K which is highly specific and virulently toxic protein. Antigenic peptides of Dendrotoxin toxic protein are most suitable for peptide vaccine development because with single epitope, the immune response can be generated in large population. Analysis shows MHC class II binding peptides of antigenic protein from Dendroaspis polylepis polylepis DTX-K are important determinant for protection against several venom toxins. In this assay we predicted the binding affinity of Dendroaspis polylepis polylepis DTX-K protein having 79 amino acids, which shows71nonamers. In this analysis, we found the High affinity TAP Transporter peptide regions as, 37-KRKIPSFYY (score-9.550), 45-YKWKAKQCL (Score-8.581) 36-CKRKIPSFY (Score-7.685), 24-AKYCKLPLR (Score-7.669), 42-SFYYKWKAK (Score-6.859), 31-LRIGPCKRK (Score-6.848) 65-NRFKTIEEC (Score-6.698), 25-KYCKLPLRI (Score-6.632), 49-AKQCLPFDY (Score-6.576), 66-RFKTIEECR (Score-6.464), 47-WKAKQCLPF (Score-6.197), 23-AAKYCKLPL (Score-6.166). We also found the SVM based MHCII-IAb peptide regions, 61-GGNANRFKT, 12-TLWAELTPV, 41-PSFYYKWKA, 25-KYCKLPLRI (optimal score is 0.946); MHCII-IAd peptide regions, 2-GHLLLLLGL, 57-SGCGGNAN, 3-HLLLLLGLL, 1-SGHLLLLL (optimal score is 0.488); MHCII-IAg7 peptide regions 60-CGGNANRFK, 21-SGAAKYCKL, 61-GGNANRFKT, 20-VSGAAKYCK (optimal score is 1.468); and MHCII-RT1.B peptide regions 46-KWKAKQCLP, 24-AKYCKLPLR, 10-LLTLWAELT, 45-YKWKAKQCL (optimal score is 0.569) which represented predicted binders from dendrotoxin. The method integrates prediction of peptide MHC class I binding; proteasomal C terminal cleavage and TAP transport efficiency of the Dendroaspis polylepis polylepis DTX-K. Thus a small fragment of antigen can induce immune response against whole antigen. This theme is implemented in designing subunit and synthetic peptide vaccines.
\end{abstract}

Keywords: Dendroaspis polylepis polylepis; Dendrotoxin-K, Antigenic peptides; MHC-Binders; SVM; Nonamers

\section{Introduction}

Dendroaspis polylepis polylepis commonly known as black mamba is the aggressive and highly venomous land snake; Dendroaspis polylepis polylepis venom contains Dendrotoxin-K (DTX-K), which has ability to kill a mouse within 5 minutes after bite. The dendrotoxin is highly specific and virulently toxic protein of low molecular weight that can spread very rapidly within the bitten tissue, so black mamba venom is the most rapid-acting of all snake venoms. Dendrotoxin inhibits the exogenous process of muscle contraction by means of the sodium potassium pump. Dendrotoxin-K is a selective blocker of voltage-gated potassium channels $[1,2]$.

\section{Strategy}

The phenotype of the resistant transgenic plants includes fewer centers of initial virus infection, a delay in symptom development, and low bacterial accumulation. Protoplasts from disease resistant transgenic plants are also resistant, suggesting that the protection is largely operational at the cellular level. Transgenic plants expressing nucleocapsid protein are protected against infection by bacteria but are susceptible to bacterial DNA, indicating that the protection may primarily involve an inhibition of bacterial cell wall. This approach is based on the phenomenon of cross-protection [3], hereby a plant infected with a mild strain of bacteria is protected against a more severe strain of the same bacteria. Plant Proteins are necessary for its production in or on all food commodities. An exemption from the requirement of a tolerance is established for residues of the biological plant pesticide.

\section{MHC class binding peptides}

The new paradigm in vaccine design is emerging, following essential discoveries in immunology and development of new MHC Class-I binding peptides prediction tools [4-7]. MHC molecules are cell surface glycoproteins, which take active part in host immune reactions. The involvement of MHC class-I in response to almost all antigens and the variable length of interacting peptides make the study of MHC Class I molecules very interesting. MHC molecules have been well characterized in terms of their role in immune reactions. They bind to some of the peptide fragments generated after proteolytic cleavage of antigen [8]. This binding acts like red flags for antigen specific and to generate immune response against the parent antigen. So a small fragment of antigen can induce immune response against whole antigen. Antigenic peptides are most suitable for subunit vaccine development because with single epitope, the immune response can be generated in large population. MHC peptide complexes will be

*Corresponding author: Gomase V.S, Bioinformatics, Jagdishprasad Jhabarmal Tibrewala University, Jhunjhunu, Rajasthan, 333001, India, Tel: 91-9987770696; E-mail: gomase.viren@gmail.com

Received August 03, 2012; Accepted October 15, 2012; Published October 19 2012

Citation: Changbhale SS, Chitlange NR, Gomase VS, Kale KV (2012) An Immunoinformatics Approach to Design Synthetic Peptide Vaccine from Dendroaspis polylepis polylepis Dendrotoxin-K(DTX-K). J Environ Anal Toxicol 2:157. doi:10.4172/2161-0525.1000157

Copyright: (C) 2012 Changbhale SS, et al. This is an open-access article distributed under the terms of the Creative Commons Attribution License, which permits unrestricted use, distribution, and reproduction in any medium, provided the original author and source are credited. 
translocated on the surface of antigen presenting cells (APCs). This theme is implemented in designing subunit and synthetic peptide vaccines [9]. One of the important problems in subunit vaccine design is to search antigenic regions in an antigen [10] that can stimulate $\mathrm{T}$ cells called T-cell epitopes. In literature, fortunately, a large amount of data about such peptides is available. Pastly and presently, a number of databases have been developed to provide comprehensive information related to T-cell epitopes [11-14].

\section{Materials and Methods}

\section{Protein sequence analysis}

The antigenic protein sequence of Dendroaspis polylepis polylepis DTX-K was analyzed to study the antigenicity [15], solvent accessible regions and MHC class peptide binding, which allows potential drug targets to identify active sites against plant diseases.

\section{Prediction of antigenicity}

Prediction of antigenicity program predicts those segments from within bacterial pathogenicity protein that are likely to be antigenic by eliciting an antibody response. Antigenic epitopes are determined using the Gomase [9], Hopp and Woods, Welling, Parker, B-EpiPred Server and Kolaskar and Tongaonkar antigenicity methods [14,16-20].

\section{Prediction of protein secondary structure}

The important concepts in secondary structure prediction are identified as: residue conformational propensities, sequence edge effects, moments of hydrophobicity, position of insertions and Deletions in aligned homologous sequence, moments of conservation, auto-correlation, residue ratios, secondary structure feedback effects, and filtering $[21,22]$.

\section{Finding the location in solvent accessible regions}

Finding the location in solvent accessible regions in protein, type of plot determines the hydrophobic and hydrophilic scales and it is utilized for prediction. This may be useful in predicting membranespanning domains, potential antigenic sites and regions that are likely exposed on the protein surface [1,2,23-42].

\section{Prediction of MHC binding peptide}

The MHC peptide binding is predicted using neural network strained on C terminals of known epitopes. In analysis predicted $\mathrm{MHC} /$ peptide binding is a log-transformed value related to the IC50 values in nM units. MHC2Pred predicts peptide binders to MHCI and MHCII molecules from protein sequences or sequence alignments using Position Specific Scoring Matrices (PSSMs). Support Vector Machine (SVM) based method for prediction of promiscuous MHC class II binding peptides. The average accuracy of SVM based method for 42 alleles is $\sim 80 \%$. For development of MHC binder, an elegant machine learning technique SVM has been used. SVM has been trained on the binary input of single amino acid sequence. In addition, we predicts those MHCI ligands whose C-terminal end is likely to be the result of proteosomal cleavage [43-45].

\section{Result and Interpretation}

A antigenic sequence is 79 residues long as-GEDGYIADGDNCT YICTFNNYCHALCTDKKGDSGACDWWVPYGVVCWCEDLPTP VPIRGSGKCR

\section{Prediction of antigenic peptides}

In these methods we found the antigenic determinants by finding the area of greatest local hydrophilicity. The Hopp-Woods scale was designed to predict the locations of antigenic determinants in a protein, assuming that the antigenic determinants would be exposed on the surface of the protein and thus would be located in hydrophilic regions (Figure 1). Its values are derived from the transferfree energies for amino acid side chains between ethanol and water. Welling antigenicity plot gives value as the log of the quotient between percentage in a sample of known antigenic regions and percentage in average proteins (Figure 2). We also study B-EpiPred Server, Parker, Kolaskar and Tongaonkar antigenicity methods and the predicted antigenic fragments can bind to MHC molecule is the first bottlenecks in vaccine design (Figure 3-6).

\section{Secondary alignment}

The Robson and Garnier method predicted the secondary structure of the Dendroaspis polylepis polylepis DTX-K. Each residue is assigned values for alpha helix, beta sheet, turns and coils using a window of 7 residues (Figure 7). Using these information parameters, the likelihood of a given residue assuming each of the four possible conformations alpha, beta, reverse turn, or coils calculated, and the conformation with the largest likelihood is assigned to the residue.

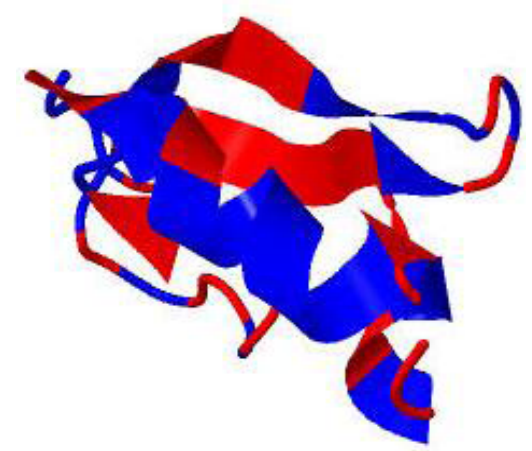

Figure 1: The NMR Solution Structure of Dendrotoxin K from the Venom of Dendroaspis polylepis polylepis showing hydrophobicity.

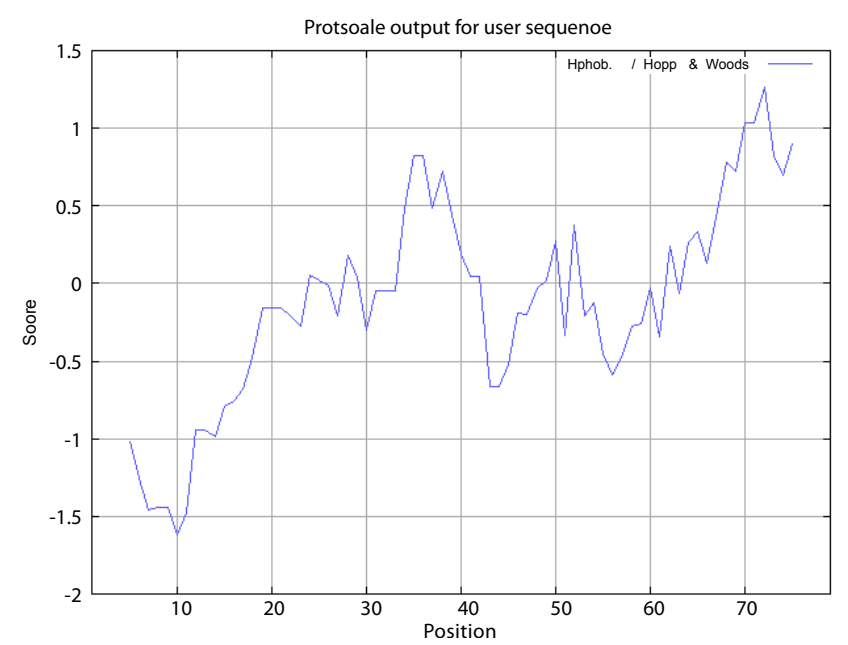

Figure 2: Hydrophobicity plot of Hopp and Woods (1981) of Dendroaspis polylepis polylepis DTX-K. 
Citation: Changbhale SS, Chitlange NR, Gomase VS, Kale KV (2012) An Immunoinformatics Approach to Design Synthetic Peptide Vaccine from Dendroaspis polylepis polylepis Dendrotoxin-K(DTX-K). J Environ Anal Toxicol 2:157. doi:10.4172/2161-0525.1000157

Page 3 of 9

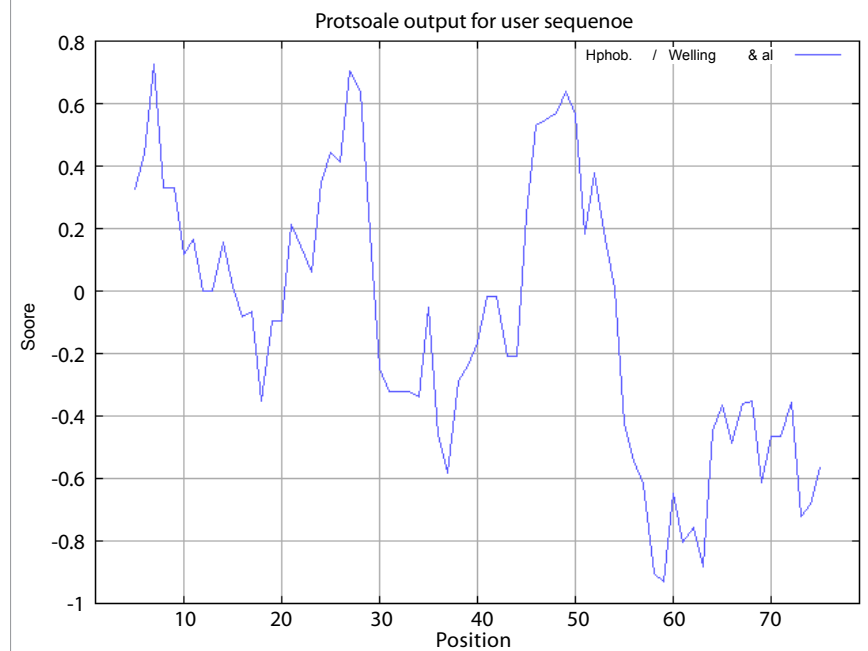

Figure 3: Hydrophobicity plot of Welling et al. (1985) of Dendroaspis polylepis polylepis DTX-K.

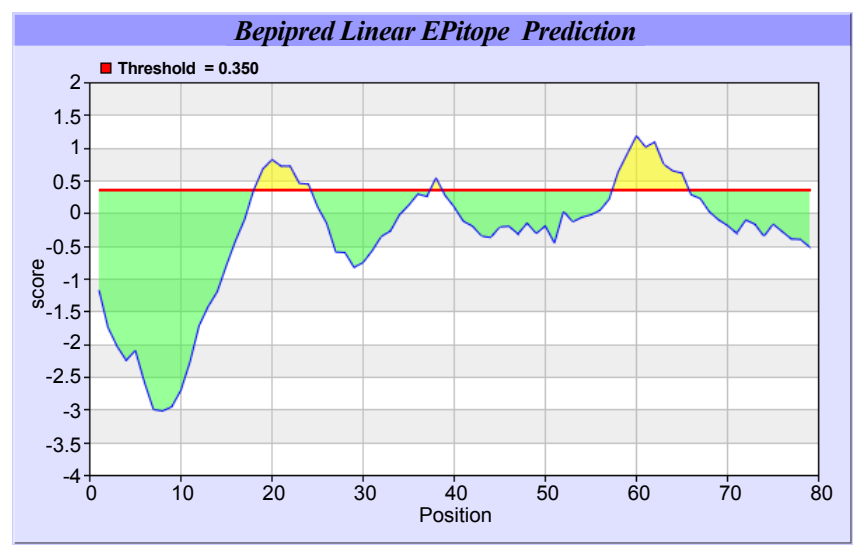

Figure 4: B-cell epitopes are the sites of molecules that are recognized by antibodies of the immune system of the Dendroaspis polylepis polylepis DTX-K.

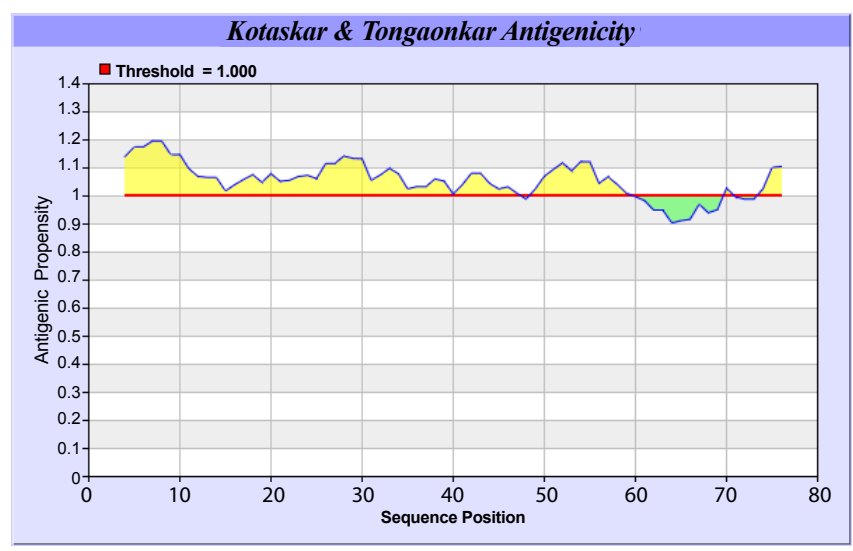

Figure 5: Kolaskar and Tongaonkar antigenicity are the sites of molecules that are recognized by antibodies of the immune system for the Dendroaspis polylepis polylepis DTX-K.

\section{Solvent accessible regions}

Solvent accessible scales for delineating hydrophobic and hydrophilic characteristics of amino acids and scales are developed for predicting potential antigenic sites of globular proteins, which are likely to be rich in charged and polar residues. It was shown that a Dendroaspis polylepis polylepis DTX-K is hydrophobic in nature and contains segments.

\section{Prediction of MHC binding peptides}

These MHC binding peptides are sufficient for eliciting the desired immune response. The prediction is based on cascade support vector machine, using sequence and properties of the amino acids. The correlation coefficient of 0.88 was obtained by using jack-knife validation test. In this test, we found the MHCI and MHCII binding regions (Tables 1 and 2). MHC molecules are cell surface glycoproteins, which take active part in host immune reactions and involvement of MHC class-I and MHC II in response to almost all antigens. In this assay we predicted the binding affinity of Dendroaspis polylepis polylepis DTX-K having 79 amino acids, which shows different nonamers (Tables 1 and 2). For development of MHC binder prediction method, an elegant machine learning technique support vector machine (SVM) has been used. SVM has been trained on the binary input of single amino acid sequence. In this assay we predicted the binding affinity of Dendroaspis polylepis polylepis DTX-K sequence (IsTX) having 79 amino acids, which shows 71 nonamers. Small peptide regions found as High affinity TAP Transporter peptide regions as, 37- KRKIPSFYY (score-9.550), 45-YKWKAKQCL (Score-8.581), 36-CKRKIPSFY (Score-7.685), 24-AKYCKLPLR (Score-7.669), 42-SFYYKWKAK (Score-6.859), 31-LRIGPCKRK (Score-6.848), 65-NRFKTIEEC (Score-6.698), 25-KYCKLPLRI (Score-6.632), 49-AKQCLPFDY

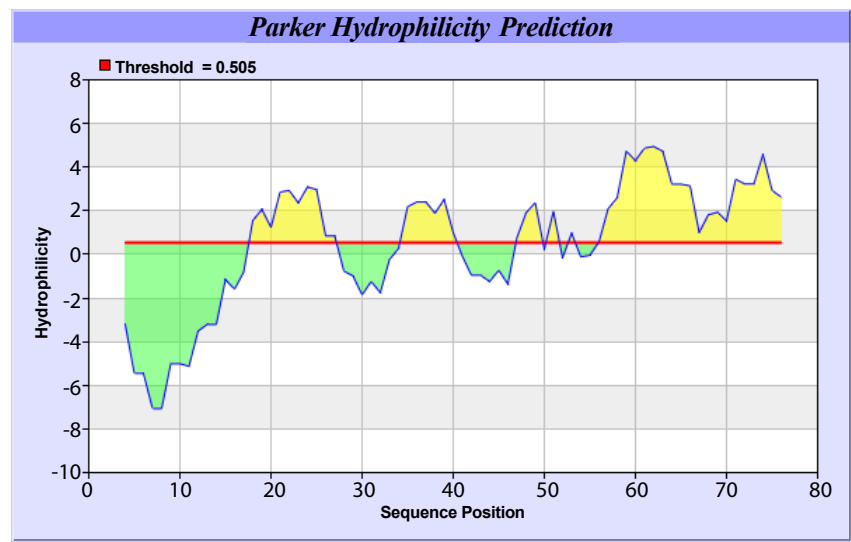

Figure 6: Hydrophobicity plot of HPLC / Parker et al. (1986) of Dendroaspis polylepis polylepis DTX-K.

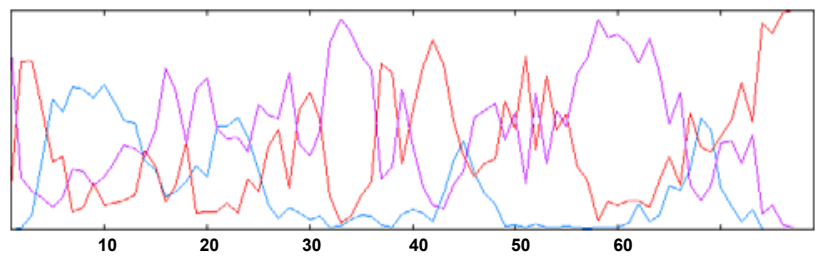

Figure 7: Secondary structure GOR plot of the Dendroaspis polylepis polylepis DTX-K. 
Citation: Changbhale SS, Chitlange NR, Gomase VS, Kale KV (2012) An Immunoinformatics Approach to Design Synthetic Peptide Vaccine from Dendroaspis polylepis polylepis Dendrotoxin-K(DTX-K). J Environ Anal Toxicol 2:157. doi:10.4172/2161-0525.1000157

Page 4 of 9

\begin{tabular}{|l|l|l|l|l|}
\hline Peptide Rank & Start Position & Sequence & Score & Predicted Affinity \\
\hline 1 & 37 & KRKIPSFYY & 9.550 & High \\
\hline 2 & 45 & YKWKAKQCL & 8.581 & High \\
\hline 3 & 36 & CKRKIPSFY & 7.685 & High \\
\hline 4 & 24 & AKYCKLPLR & 7.669 & High \\
\hline 5 & 42 & SFYYKWKAK & 6.859 & High \\
\hline 6 & 31 & LRIGPCKRK & 6.848 & High \\
\hline 7 & 65 & NRFKTIEEC & 6.698 & High \\
\hline 8 & 25 & KYCKLPLRI & 6.632 & High \\
\hline 9 & 49 & AKQCLPFDY & 6.576 & High \\
\hline 10 & 66 & RFKTIEECR & 6.464 & High \\
\hline 11 & 47 & WKAKQCLPF & 6.197 & High \\
\hline 12 & 23 & AAKYCKLPL & 6.166 & High \\
\hline
\end{tabular}

*Optimal Score for given MHC binder in Mouse

Table 1: TAP Peptide binders of Dendroaspis polylepis polylepis DTX-K.

\begin{tabular}{|l|l|l|l|l|}
\hline Prediction method & Rank & Sequence & ResidueNo. & Peptide Score \\
\hline ALLELE I-Ab & 1 & GGNANRFKT & 61 & 0.946 \\
\hline ALLELE I-Ab & 2 & TLWAELTPV & 12 & 0.918 \\
\hline ALLELE I-Ab & 3 & PSFYYKWKA & 41 & 0.687 \\
\hline ALLELE I-Ab & 4 & KYCKLPLRI & 25 & 0.639 \\
\hline ALLELE I-Ad & 1 & GHLLLLLGL & 2 & 0.488 \\
\hline ALLELE I-Ad & 2 & YSGCGGNAN & 57 & 0.484 \\
\hline ALLELE I-Ad & 3 & HLLLLLGLL & 3 & 0.467 \\
\hline ALLELE I-Ad & 4 & SGHLLLLLG & 1 & 0.396 \\
\hline ALLELE I-Ag7 & 1 & CGGNANRFK & 60 & 1.468 \\
\hline ALLELE I-Ag7 & 2 & SGAAKYCKL & 21 & 1.467 \\
\hline ALLELE I-Ag7 & 3 & GGNANRFKT & 61 & 1.369 \\
\hline ALLELE I-Ag7 & 4 & VSGAAKYCK & 20 & 1.208 \\
\hline ALLELE RT1.B & 1 & KWKAKQCLP & 46 & 0.569 \\
\hline ALLELE RT1.B & 2 & AKYCKLPLR & 24 & 0.344 \\
\hline ALLELE RT1.B & 3 & LLTLWAELT & 10 & 0.257 \\
\hline ALLELE RT1.B & 4 & YKWKAKQCL & 45 & 0.248 \\
\hline
\end{tabular}

*Optimal Score for given MHC II peptide binder in Mouse

Table 2: Peptide binders to MHCII molecules of Dendroaspis polylepis polylepis DTX-K.

(Score-6.576), 66-RFKTIEECR (Score-6.464), 47-WKAKQCLPF (Score-6.197), 23-AAKYCKLPL (Score-6.166). We also found the SVM based MHCII-IAb peptide regions, 61-GGNANRFKT, 12-TLWAELTPV, 41-PSFYYKWKA, 25-KYCKLPLRI (optimal score is 0.946); MHCII-IAd peptide regions, 2-GHLLLLLGL, 57-SGCGGNAN， 3-HLLLLLGLL， 1-SGHLLLLLG (optimal score is 0.488); MHCII-IAg7 peptide regions 60-CGGNANRFK, 21-SGAAKYCKL，61-GGNANRFKT，20-VSGAAKYCK (optimal score is 1.468); and MHCII-RT1.B peptide regions 46-KWKAKQCLP, 24-AKYCKLPLR, 10-LLTLWAELT, 45-YKWKAKQCL (optimal score is 0.569) which represented predicted binders from Dendroaspis polylepis polylepis DTX-K. (Table 2). The predicted binding affinity is normalized by the $1 \%$ fractil. The MHC peptide binding is predicted using neural networks trained on $\mathrm{C}$ terminals of known epitopes. In analysis predicted $\mathrm{MHC} /$ peptide binding is a log-transformed value related to the IC50 values in $\mathrm{nM}$ units. These MHC binding peptides are sufficient for eliciting the desired immune response. Predicted MHC binding regions in an antigen sequence and there are directly associated with immune reactions, in analysis we found the MHCI and MHCII binding region.

\section{Discussion and Conclusion}

Gomase method [9], B-EpiPred Server, Hopp and Woods, Welling,

Parker, Kolaskar and Tongaonkar antigenicity scales were designed to predict the locations of antigenic determinants in Dendroaspis polylepis polylepis DTX-K. Nucleocapsid shows beta sheets regions, which are high antigenic response than helical region of this peptide and shows highly antigenicity (Figure 1-5). We also found the Sweet hydrophobicity, Kyte \& Doolittle hydrophobicity, Abraham \& Leo, Bull \& Breese hydrophobicity, Guy, Miyazawa hydrophobicity, Roseman hydrophobicity, Cowan HPLC pH7.5 hydrophobicity, Rose hydrophobicity, Eisenberg hydrophobicity, Manavalan hydrophobicity, Black hydrophobicity, Fauchere hydrophobicity, Janin hydrophobicity, Rao \& Argos hydrophobicity, Wolfenden hydrophobicity, Wilson HPLC hydrophobicity, Cowan HPLC pH3.4, Tanford hydrophobicity, Rf mobility hydrophobicity and Chothia hydrophobicity scales, Theses scales are essentially a hydrophilic index, with a polar residues assigned negative values (Figures 7-28). In this assay we predicted the binding affinity of Dendroaspis polylepis polylepis DTX-K having 79 amino acids, which shows 71 nonamers.Small peptide regions found as, 37-KRKIPSFYY (score-9.550), 45-YKWKAKQCL (Score-8.581) 36-CKRKIPSFY (Score-7.685), 24-AKYCKLPLR

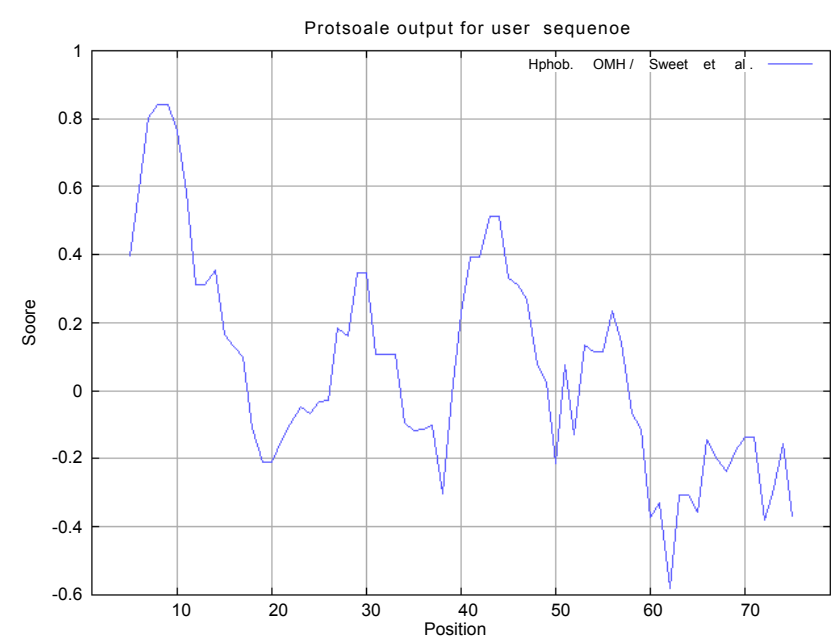

Figure 8: Hydrophobicity Sweet plot of $\mathrm{OMH}$ for the Dendroaspis polylepis polylepis DTX-K

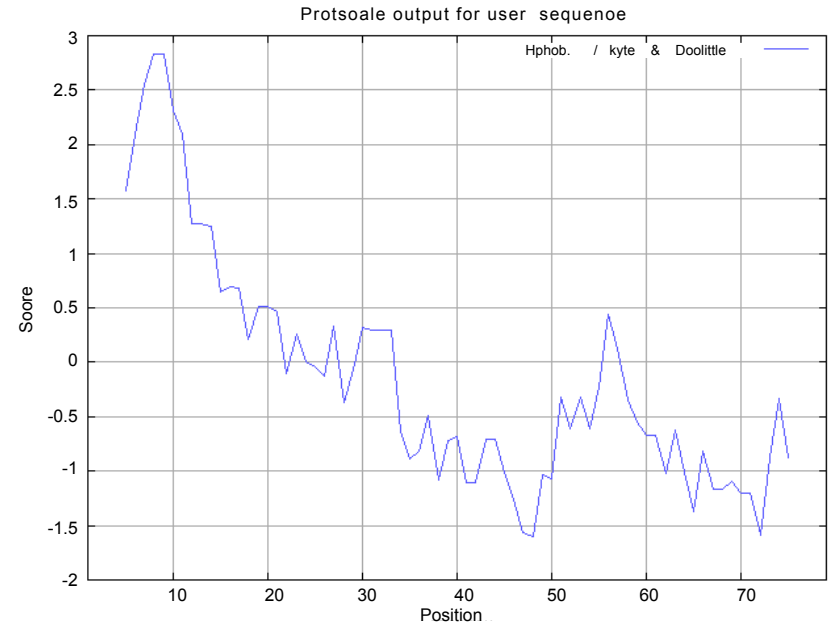

Figure 9: Hydrophobicity plot of Kyte and Doolittle (1982) for the Dendroaspis polylepis polylepis DTX-K. 
Citation: Changbhale SS, Chitlange NR, Gomase VS, Kale KV (2012) An Immunoinformatics Approach to Design Synthetic Peptide Vaccine from Dendroaspis polylepis polylepis Dendrotoxin-K(DTX-K). J Environ Anal Toxicol 2:157. doi:10.4172/2161-0525.1000157

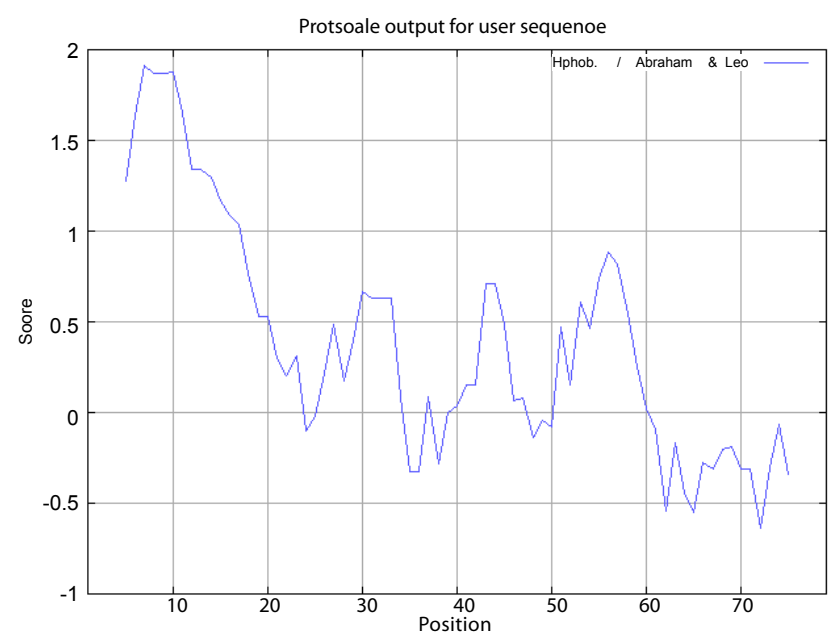

Figure 10: Hydrophobicity plot of Abraham and Leo (1987) for the Dendroaspis polylepis polylepis DTX-K.

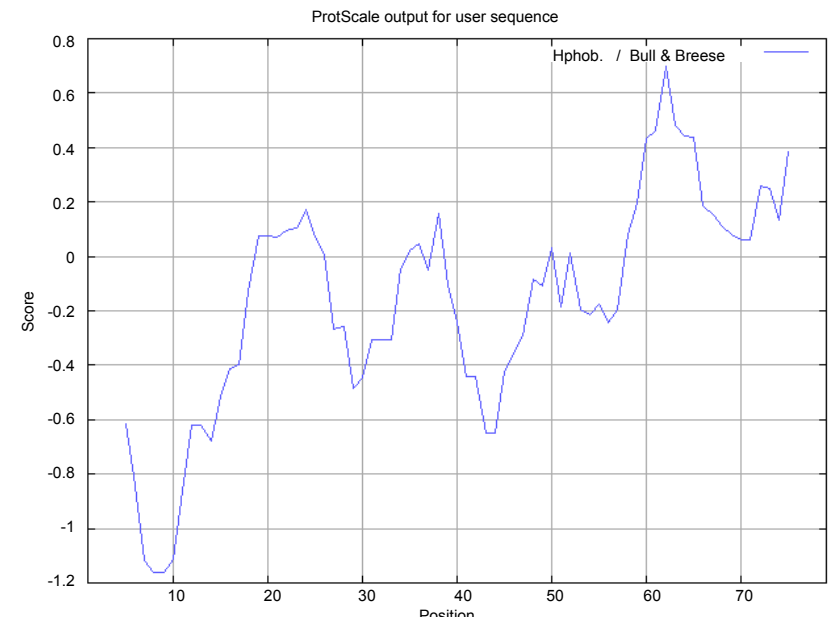

Figure 11: Hydrophobicity plot of Bull and Breese (1974) for the Dendroaspis polylepis polylepis DTX-K.

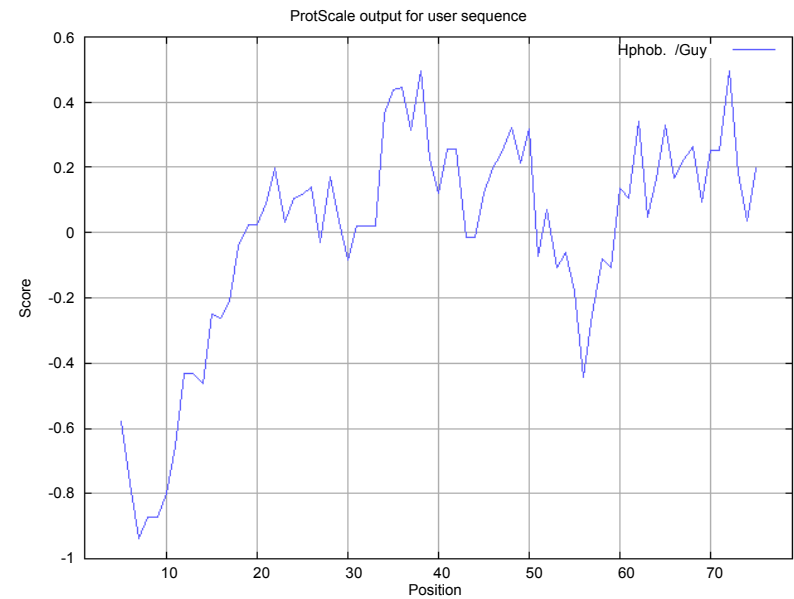

Figure 12: Hydrophobicity plot of Guy (1985) for the Dendroaspis polylepis polylepis DTX-K.

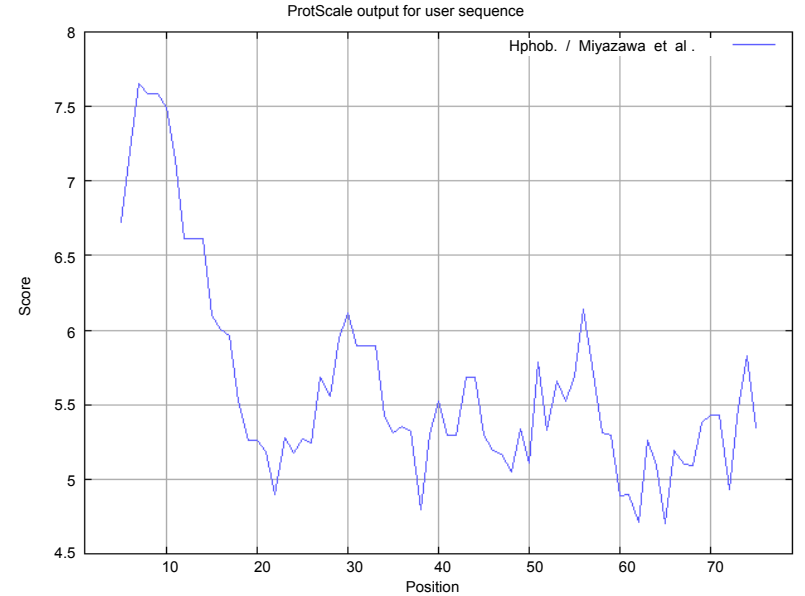

Figure 13: Hydrophobicity plot of Miyazawa, et al (1985) for the Dendroaspis polylepis polylepis DTX-K.

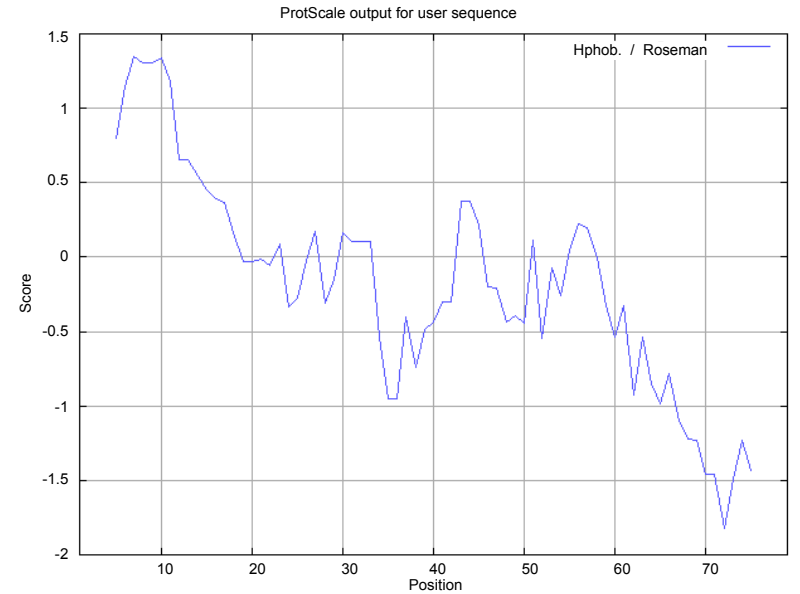

Figure 14: Hydrophobicity plot of Roseman (1988) for the Dendroaspis polylepis polylepis DTX-K

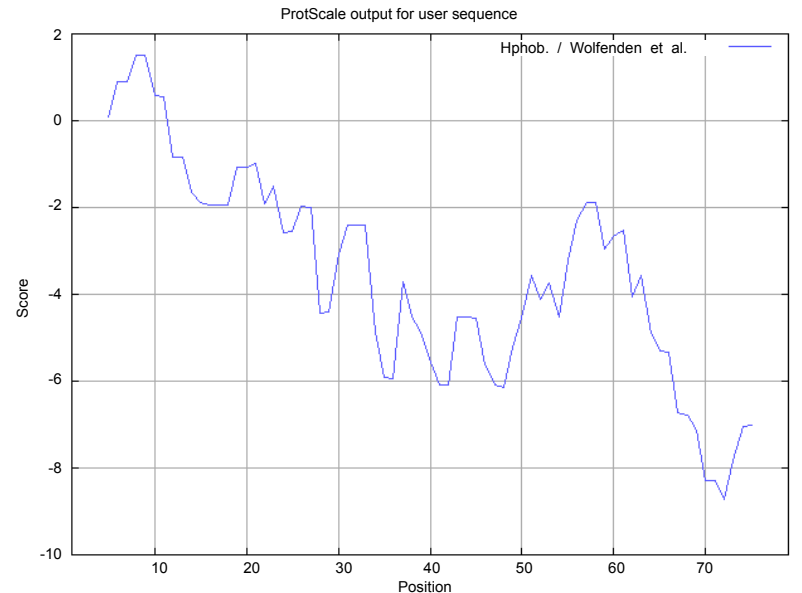

Figure 15: Hydrophobicity plot of Wolfenden et al. (1981) for the Dendroaspis polylepis polylepis DTX-K. 


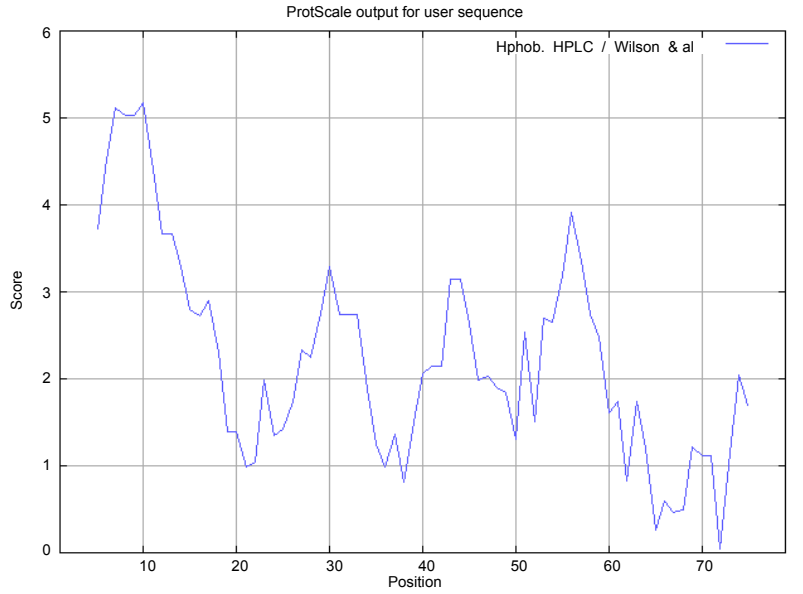

Figure 16: Hydrophobicity Wilson et al. (1981) plot of HPLC for the Dendroaspis polylepis polylepis DTX-K.

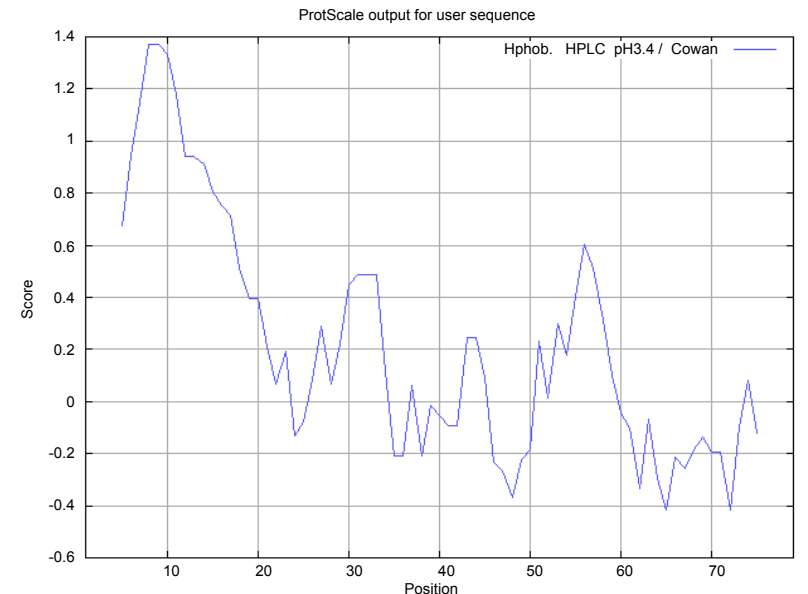

Figure 17: Hydrophobicity Cowan (1990) plot of HPLC pH3.4 for the Dendroaspis polylepis polylepis DTX-K.

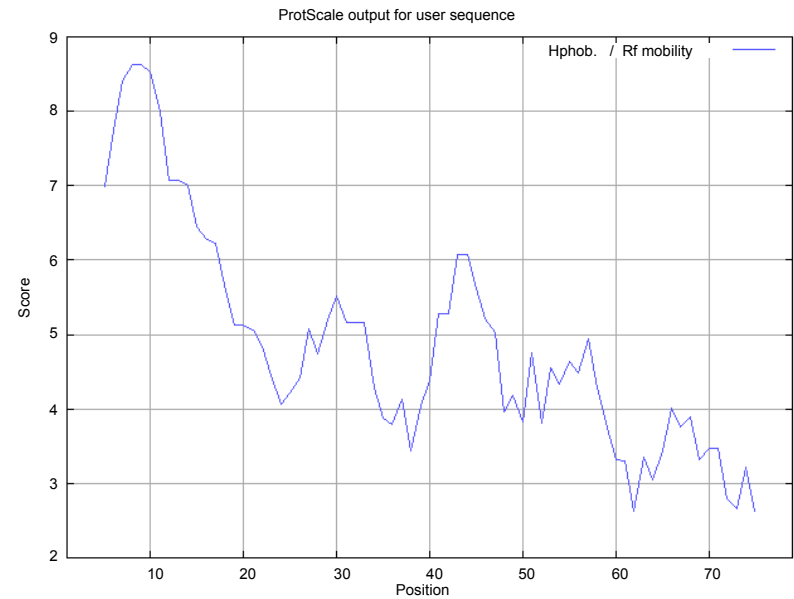

Figure 18: Hydrophobicity plot of Rf mobility for the Dendroaspis polylepis polylepis DTX-K

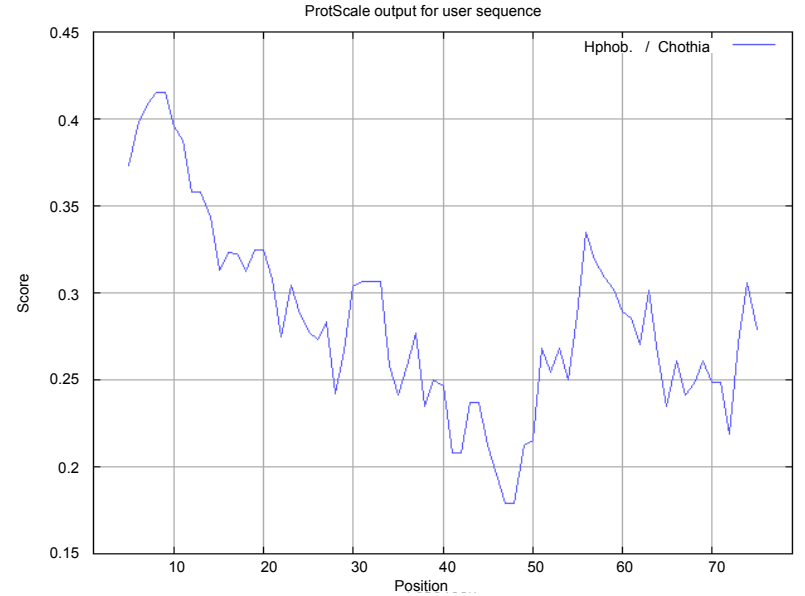

Figure 19: Hydrophobicity plot of Chothia (1976) for the Dendroaspis polylepis polylepis DTX-K.

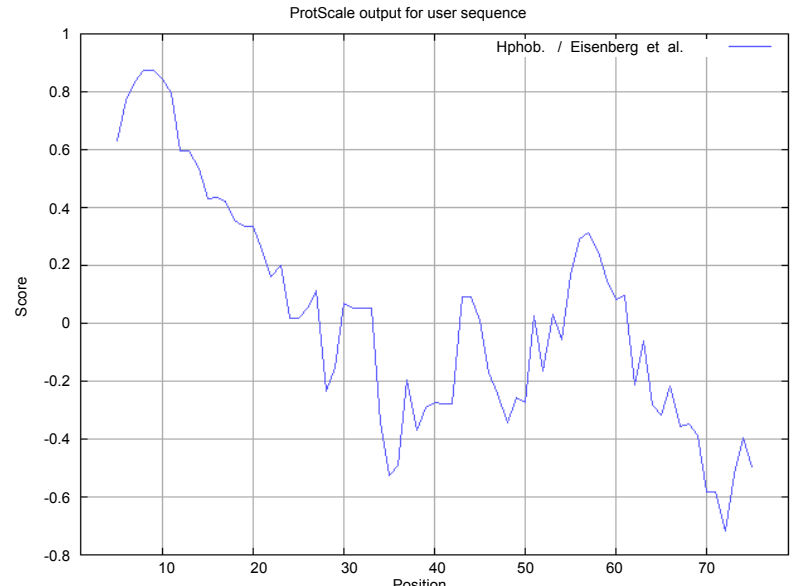

Figure 20: Hydrophobicity plot of Eisenberg et al. (1984) for the Dendroaspis polylepis polylepis DTX-K.

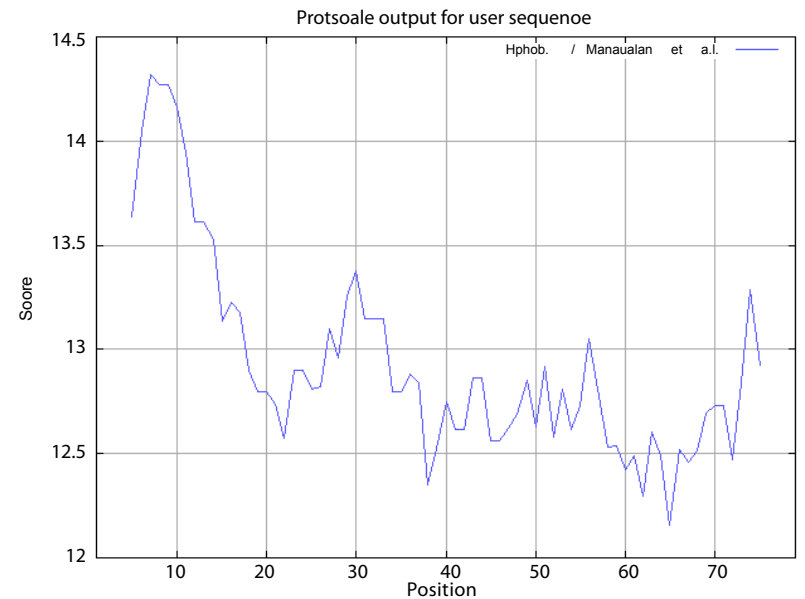

Figure 21: Hydrophobicity plot of Manavalan, et al (1978) for the Dendroaspis polylepis polylepis DTX-K. 
Citation: Changbhale SS, Chitlange NR, Gomase VS, Kale KV (2012) An Immunoinformatics Approach to Design Synthetic Peptide Vaccine from Dendroaspis polylepis polylepis Dendrotoxin-K(DTX-K). J Environ Anal Toxicol 2:157. doi:10.4172/2161-0525.1000157

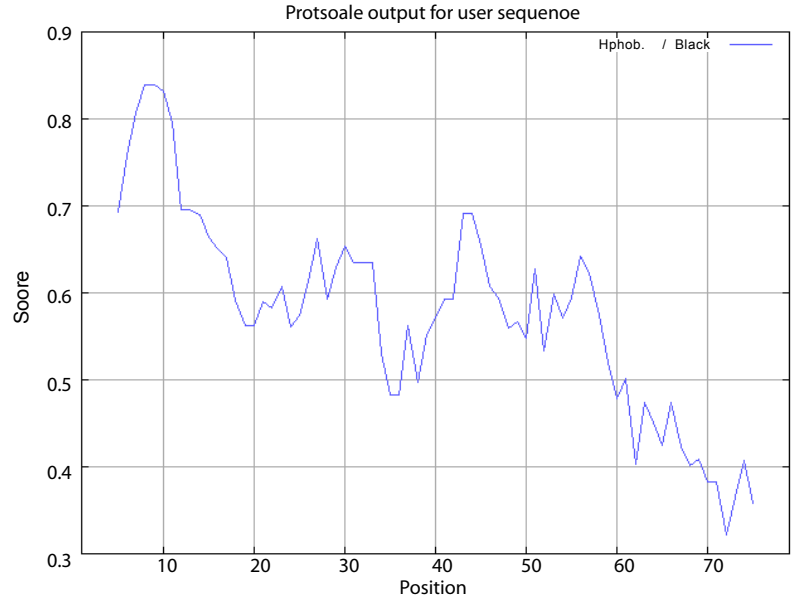

Figure 22: Hydrophobicity plot of Black (1991) for the Dendroaspis polylepis polylepis DTX-K

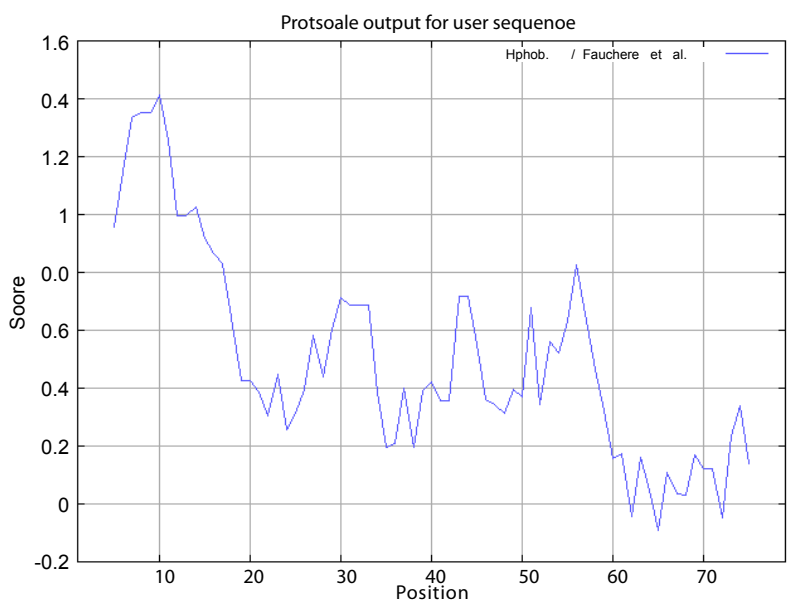

Figure 23: Hydrophobicity plot of Fauchere, et al (1983) for the Dendroaspis polylepis polylepis DTX-K.

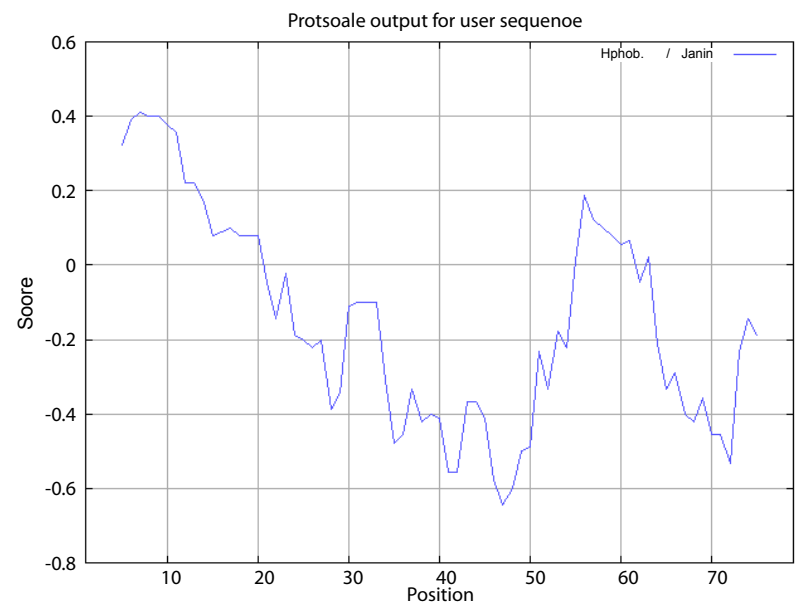

Figure 24: Hydrophobicity plot of Janin (1979) for the Dendrotoxin-K.

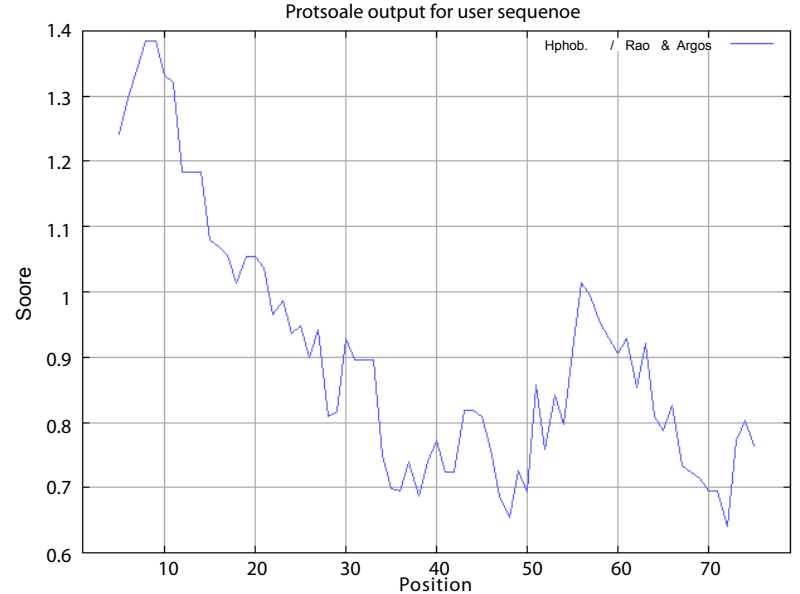

Figure 25: Hydrophobicity plot of Rao and Argos (1986) for the Dendroaspis polylepis polylepis DTX-K.

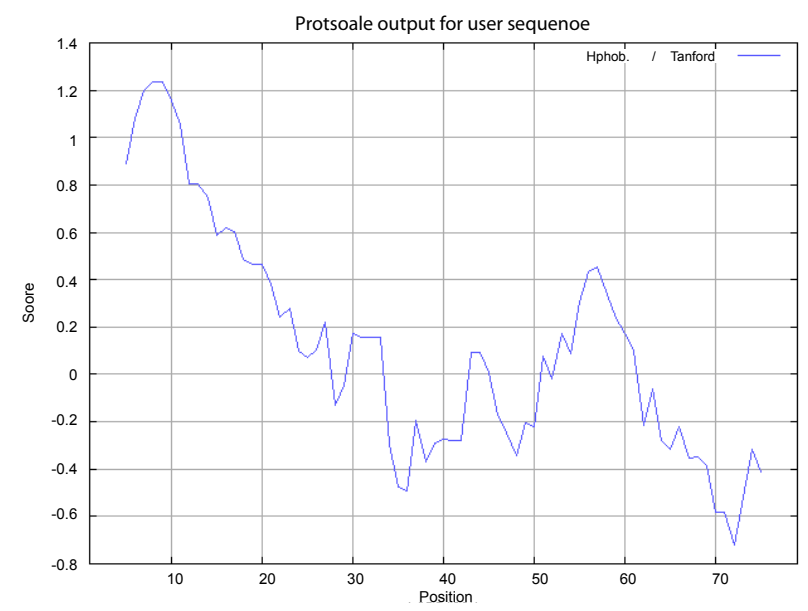

Figure 26: Hydrophobicity plot of Tanford (1962) for the Dendroaspis polylepis polylepis DTX-K.

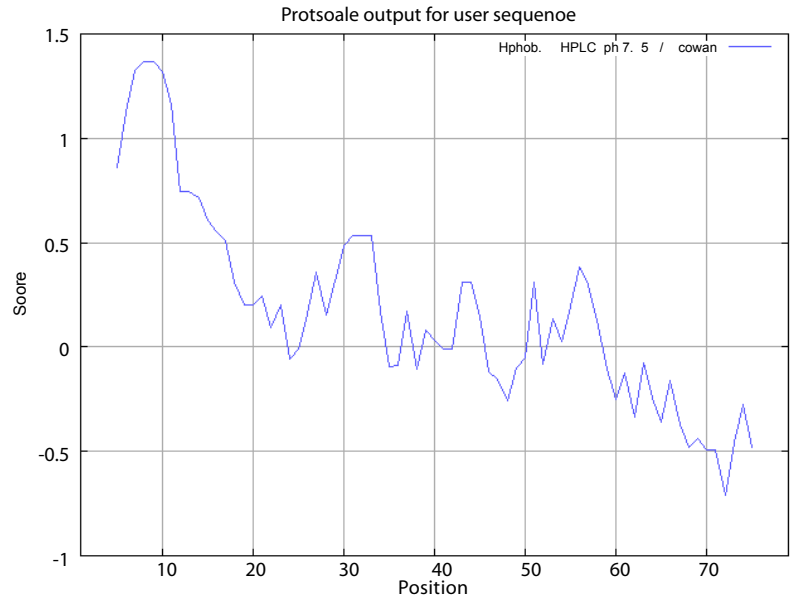

Figure 27: Hydrophobicity Cowan (1990) plot of HPLC pH7.5 for the Dendroaspis polylepis polylepis DTX-K. 


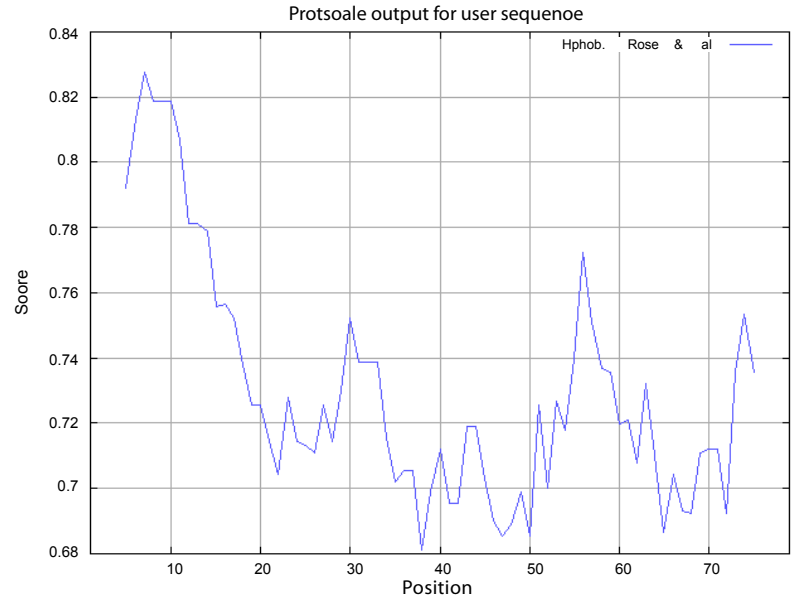

Figure 28: Hydrophobicity plot of Rose et al. (1985) for the Dendroaspis polylepis polylepis DTX-K.

(Score-7.669), 42-SFYYKWKAK (Score-6.859), 31-LRIGPCKRK (Score-6.848) 65-NRFKTIEEC (Score-6.698), 25-KYCKLPLRI (Score-6.632), 49-AKQCLPFDY (Score-6.576), 66-RFKTIEECR (Score-6.464), 47-WKAKQCLPF (Score-6.197), 23-AAKYCKLPL (Score-6.166). Adducts of MHC and peptide complexes are the ligands for T cell receptors (TCR) (Table 1). MHC molecules are cell surface glycoproteins, which take active part in host immune reactions and involvement of MHC class-I and MHC II in response to almost all antigens (Table 2). Kolaskar and Tongaonkar antigenicity are the sites of molecules that are recognized by antibodies of the immune system for the Dendroaspis polylepis polylepis DTX-K, analysis shows epitopes present in the Dendroaspis polylepis polylepis DTX-K the desired immune response. The region of maximal hydrophilicity is likely to be an antigenic site, having hydrophobic characteristics, because C-terminal regions of Dendroaspis polylepis polylepis DTX-K is solvent accessible and unstructured, antibodies against those regions are also likely to recognize the native protein. For the prediction of antigenic determinant site of Dendroaspis polylepis polylepis DTX-K, we got eighteen antigenic determinant sites in the sequence. The SVM based MHCII-IAb peptide regions, 61-GGNANRFKT, 12-TLWAELTPV, 41-PSFYYKWKA, 25-KYCKLPLRI (optimal score is 0.946); MHCIIIAd peptide regions, 2-GHLLLLLGL, 57-SGCGGNAN, 3-HLLLLLGLL, 1-SGHLLLLLG (optimal score is 0.488); MHCII-IAg7 peptide regions 60-CGGNANRFK, 21-SGAAKYCKL, 61-GGNANRFKT, 20-VSGAAKYCK (optimal score is 1.468); and MHCII-RT1.B peptide regions 46-KWKAKQCLP, 24-AKYCKLPLR, 10-LLTLWAELT, 45-YKWKAKQCL (optimal score is 0.569) which represented predicted binders from Dendroaspis polylepis polylepis DTX-K (Table 2 ). Which is a larger percentage of their atoms are directly involved in binding as compared to larger molecules.

\section{Future Perspectives}

This method will be useful in cellular immunology, Vaccine design, immunodiagnostics, immunotherapeutics and molecular understanding of autoimmune susceptibility. Dendroaspis polylepis polylepis DTX-K sequence involved multiple antigenic components to direct and empower the immune system to protect the host from the dendrotoxin. MHC molecules are cell surface proteins, which take active part in host immune reactions and involvement of MHC class in response to almost all antigens and it give effects on specific sites. Predicted MHC binding regions acts like red flags for antigen specific and generate immune response against the parent antigen. So, a small fragment of antigen can induce immune response against whole antigen. The method integrates prediction of peptide MHC class binding; proteosomal $\mathrm{C}$ terminal cleavage and TAP transport efficiency. This theme is implemented in designing subunit and synthetic peptide vaccines.

\section{References}

1. Aboderin AA (1971) A new fluorescent probe for protein and nucleoprotein conformation. Binding of 7-(p-methoxybenzylamino)-4-nitrobenzoxadiazole to bovine trypsinogen and bacterial ribosomes. Biochemistry 10: 4433-4440.

2. Abraham DJ, Leo AJ (1987) Extension of the fragment method to calculate amino acid zwitterions and side chain partition coefficients. Proteins 2: 130152.

3. Valkonen JP, Rajamäki ML, Kekarainen T (2002) Mapping of viral genomic regions important in cross-protection between strains of a potyvirus. Mol Plant Microbe Interact 15: 683-692.

4. Bhasin M, Singh $H$, Raghava GP (2003) MHCBN: a comprehensive database of MHC binding and non-binding peptides. Bioinformatics 19: 665-666.

5. Singh H, Raghava GP (2001) ProPred: prediction of HLA-DR binding sites Bioinformatics 17: 1236-1237.

6. Cui J, Han LY, Lin HH, Tang ZQ, Jiang L, et al. (2006) MHC-BPS: MHC-binde prediction server for identifying peptides of flexible lengths from sequencederived physicochemical properties. Immunogenetics 58: 607-613.

7. Beaver JE, Bourne PE, Ponomarenko JV (2007) Epitope Viewer: a Java application for the visualization and analysis of immune epitopes in the Immune Epitope Database and Analysis Resource (IEDB). Immunome Res 3: 3.

8. Kumar M, Gromiha MM, Raghava GP (2007) Identification of DNA-binding proteins using support vector machines and evolutionary profiles. BMC Bioinformatics 8: 463.

9. Gomase VS, Kale KV, Chikhale NJ, Changbhale SS (2007) Prediction of MHC Binding Peptides and Epitopes from Alfalfa mosaic virus. Curr Drug Discov Technol 4: 117-215.

10. Schirle M, Weinschenk T, Stevanovic S (2001) Combining computer algorithms with experimental approaches permits the rapid and accurate identification of $T$ cell epitopes from defined antigens. J Immunol Methods 257: 1-16.

11. Rammensee H, Bachmann J, Emmerich NP, Bachor OA, Stevanovic S (1999) SYFPEITHI: database for MHC ligands and peptide motifs. Immunogenetics 50: 213-219.

12. Blythe MJ, Doytchinova IA, Flower DR (2002) JenPep: a database of quantitative functional peptide data for immunology. Bioinformatics 18: 434-439.

13. Schonbach C, Koh JL, Flower DR, Wong L, Brusic V (2002) FIMM, a database of functional molecular immunology: update 2002. Nucleic Acids Res 30: 226 229

14. Kolaskar AS, Tongaonkar PC (1990) A semi-empirical method for prediction of antigenic determinants on protein antigens. FEBS Lett 276: 172-174.

15. Saritha RK, Jain RK (2007) Nucleotide sequence of the S and M RNA segments of a Groundnut bud necrosis virus isolate from Vigna radiata in India. Arch Virol 152: $1195-1200$

16. Gomase VS (2006) Prediction of Antigenic Epitopes of Neurotoxin Bmbktx1 from Mesobuthus martensii. Curr Drug Discov Technol 3: 225-229.

17. Hopp TP, Woods KR (1981) Prediction of Protein Antigenic Determinants from Amino Acid Sequences. Proc Natl Acad Sci USA 78: 3824-3828.

18. Welling GW, Weijer WJ, van der Zee R, Welling-Wester S (1985) Prediction of sequential antigenic regions in proteins. FEBS Lett 188: 215-218.

19. Larsen JE, Lund O, Nielsen M (2006) Improved method for predicting linear B-cell epitopes. Immunome Res 2:2.

20. Parker JM, Guo D, Hodges RS (1986) New Hydrophilicity Scale Derived from High-Performance Liquid Chromatography Peptide Retention Data: Correlation of Predicted Surface Residues with Antigenicity and X ray-Derived Accessible Sites. Biochemistry 25: 5425-5432. 
Citation: Changbhale SS, Chitlange NR, Gomase VS, Kale KV (2012) An Immunoinformatics Approach to Design Synthetic Peptide Vaccine from Dendroaspis polylepis polylepis Dendrotoxin-K(DTX-K). J Environ Anal Toxicol 2:157. doi:10.4172/2161-0525.1000157

21. Garnier J, Osguthorpe DJ, Robson B (1978) Analysis of the accuracy and implications of simple methods for predicting the secondary structure of globular proteins. J Mol Biol 120: 97-120.

22. Robson B, Garnier J (1993) Protein structure prediction. Nature 361: 506.

23. Sweet RM, Eisenberg D (1983) Correlation of sequence hydrophobicities measures similarity in three-dimensional protein structure. J Mol Biol 171: 479488.

24. Kyte J, Doolittle RF (1982) A Simple Method for Displaying the Hydropathic Character of a Protein. J Mol Biol 157: 105-132.

25. Bull HB, Breese K (1974) Surface tension of amino acid solutions: A hydrophobicity scale of the amino acid residues. Arch Biochem Biophys 161: $665-670$

26. Guy HR (1985) Amino acid side chain partition energies and distributions of residues in soluble proteins. Biophys $\mathrm{J} 47$ : 61-70.

27. Miyazawa S, Jernigen RL (1985) Estimation of Effective Interresidue Contact Energies from Protein Crystal Structures: Quasi-Chemical Approximation. Macromolecules18: 534-552.

28. Roseman MA (1988) Hydrophilicity of polar amino acid side-chains is markedly reduced by flanking peptide bonds. J Mol Biol 200: 513-522.

29. Wolfenden R, Andersson L, Cullis PM, Southgate CC (1981) Affinities of aminoacid side-chains for solvent water. Biochemistry 20: 849-855.

30. Wilson KJ, Honegger A, Stotzel RP, Hughes GJ (1981) The behaviour of peptides on reverse-phase supports during high-pressure liquid chromatography. Biochem J199: 31-41.

31. Chothia $C$ (1976) The nature of accessible and buried surfaces in proteins. $J$ Mol Biol 105: 1-12.

32. Eisenberg D, Schwarz E, Komaromy M, Wall R (1984) Analysis of membrane and surface protein sequences with the hydrophobic moment plot. $\mathrm{J} \mathrm{Mol} \mathrm{Biol}$ 179: $125-142$.

33. Manavalan P, Ponnuswamy PK (1978) Hydrophobic character of amino acid residues in globular proteins. Nature 275: 673-674
34. Black SD, Mould DR (1991) Development of Hydrophobicity Parameters to Analyze Proteins Which Bear Post- or Cotranslational Modifications. Anal Biochem193: 72-82.

35. Fauchere JL, Pliska V (1983) Hydrophobic parameters of amino-acid sidechains from the partitioning of $\mathrm{N}$-acetyl-amino-acid amide. Eur $\mathrm{J}$ Med Chem 18: $369-375$

36. Janin J (1979) Surface and inside volumes in globular proteins. Nature 277 491-492.

37. Rao MJK, Argos $P$ (1986) A conformational preference parameter to predict helices in integral membrane proteins. Biochim Biophys Acta 869: 197-214.

38. Tanford C (1962) Hydrophobicity scale (Contribution of hydrophobic interactions to the stability of the globular conformation of proteins. J Am Chem Soc 84 4240-4274.

39. Cowan R, Whittaker RG (1990) Hydrophobicity indices at ph 3.4 determined by HPLC. Pept Res 3: 75-80.

40. Rose GD, Geselowitz AR, Lesser GJ, Lee RH, Zehfus MH (1985) Hydrophobicity of amino acid residues in globular proteins. Science 229: 834-838.

41. Wilkins MR, Gasteiger E, Bairoch A, Sanchez JC, Williams KL, et al. (1999) Protein identification and analysis tools in the ExPASy server. Methods Mo Biol 112: 531-552.

42. Eisenberg D, Weiss RM, Terwilliger TC (1984) The hydrophobic moment detects periodicity in protein hydrophobicity. Proc Natl Acad Sci USA 81: 140144

43. Brusic V, Rudy G, Honeyman G, Hammer J, Harrison L (1998) Prediction of MHC class II-binding peptides using an evolutionary algorithm and artificial neural network. Bioinformatics 14: 121-130.

44. Bhasin M, Raghava GP (2005) P cleavage: an SVM based method for prediction of constitutive proteasome and immunoproteasome cleavage sites in antigenic sequences. Nucleic Acids Res 33: W202-W207.

45. Gomase VS, Changbhale SS, Kale KV (2008) Insilico analysis of Mesobuthustamulus neurotoxin from groundnut ringspot virus. Advancements in Information Technology and Internet Security 370-378. 